\title{
Editorial: The economics of irreversible choices
}

\author{
Giacomo Corneo · Sergio Vergalli
}

Received: 6 June 2013 / Accepted: 7 June 2013 / Published online: 20 June 2013

(C) Springer-Verlag Wien 2013

The four papers in this special issue of the Journal of Economics are a selection of the papers presented at a September 2012 workshop on "The economics of irreversible choices" at the University of Brescia. The workshop was sponsored by the two Ph.D. programs LASER (Lombardy Advanced School of Economics Research) and DEFAP (Graduate School in Public Economics and Administration). The workshop gathered scholars from around the world who are engaged in mainly theoretical research on economic decision-making in presence of irreversibility.

The notion of irreversibility plays a major role in a number of economic settings. ${ }^{1}$ Fims' investment behavior is a typical example, as investment expenditures are partly or entirely irreversible if they are firm- or industry-specific. Even investments that are not firm- or industry-specific may be partly irreversible whenever informational asymmetries give rise to a lemon problem in the market for used machines. ${ }^{2}$ One also finds several instances of irreversibility in environmental economics. By way of an example, there is a deep concern about loss of biodiversity due to the cutting of forests and the depletion of non-renewable resources which are, to some extent, irreversible. The potential irreversibility stemming from climate change that might cause desertification and the rising of sea levels is another major example. In some cases, governmental regulation and institutional arrangements can create some irreversibility. For example, capital controls may reduce the possibility for foreign or domestic investors to sell

\footnotetext{
${ }^{1}$ Early analyses include Arrow (1968) and Arrow and Fisher (1974).

2 See Dixit and Pindyck (1994), p. 8.

G. Corneo $(\bowtie)$

Department of Economics, Free University of Berlin, Berlin, Germany

e-mail: Giacomo.Corneo@fu-berlin.de

S. Vergalli

Department of Economics and Fondazione Eni Enrico Mattei, University of Brescia, Brescia, Italy
} 
their funds or assets. In labor markets, high hiring costs might make the investment in new workers partly irreversible. ${ }^{3}$ Finally, the economics of the family is a realm where irreversible choices abound - think e.g. of fertility choices and decisions about how to raise children.

Three of the articles appearing in this special issue look at irreversibility through the lens of the real options approach. An opportunity to invest in an irreversible project bears similarity with a financial call option that gives the holder the right, for some amount of time, to pay an exercise price, in return for a valuable asset. The exercise of this option is irreversible because, even if the holder of the asset can sell it to another agent, the option or the money paid to exercise the option are irretrievable. The analytical framework used to study those options can be applied to the kind of problems mentioned above - e.g. when a firm has an investment opportunity. Also in that case the firm has the option to spend money now or in the future and in return to receive a project of some value.

The article by Tsekrekos (2013) applies the real options approach to examine irreversible exit decisions by firms operating in a competitive environment. The dynamics of the output price is modeled as a mean-reverting process - which might be a more plausible price process under equilibrium conditions than the usually adopted geometric Brownian motion. He shows that mean reversion unambiguously lowers the rate of irreversible exit as compared to the case of geometric Brownian motion. Under mean reversion, the "risk discounting effect" only affects the value of the real option to exit and not the value resulting from the option exercise.

D'Alpaos et al. (2013) study a firm's decision to deliver a good in a publicprocurement setting. The supplier faces a strategic choice about delivery time subject to a penalty for delay in execution. The model features the firm's opportunistic behavior on the optimal timing when production costs are uncertain. The authors relate their theory to the evidence by testing their main results on Italian public procurement data. Their analysis shows that the supplier's incentive to delay is greater, the higher the volatility of production costs and the lower the efficiency of the judicial system.

The third article of this issue is by Di Corato et al. (2013). They employ stochastic dynamic programming to investigate land conversion decisions taken by a multitude of landholders under uncertainty about the value of environmental services and irreversible development. The authors study land conversion under competition on the market for agricultural products when voluntary and mandatory measures are combined by the government to induce habitat conservation. They show that land conversion can be delayed by paying landholders for the provision of environmental services and by limiting the individual extent of developable land.

Finally, this special issue includes a paper by Mantovi (2013) on the irreversibility of sequential economic choices concerning production and consumption. He develops a geometric approach to substitution effects and output/income effects in terms of vector fields on bundle space and establishes the benchmark relevance of homothetic models.

\footnotetext{
${ }^{3}$ See Dixit and Pindyck (1998).
} 
We are confident that the current special issue will contribute to stimulate further advances towards a better understanding of the notion of irreversibily in economics.

\section{References}

Arrow KJ (1968) Optimal capital policy with irreversible investment. In: Wolfe JN (ed) Value, capital, growth, essay in honor of Sir John Hicks. Edinburgh University Press, Edinburgh

Arrow KJ, Fisher AC (1974) Environmental preservation, uncertainty and irreversibility. Q J Econ 88:312319

D’Alpaos C, Moretto M, Valbonesi P, Vergalli S (2013) Time overruns as opportunistic behavior in public procurement. J Econ (this issue). doi:10.1007/s00712-013-0352-6

Di Corato L, Moretto M, Vergalli S (2013) Land conversion pace under uncertainty and irreversibility: too fast or too slow? J Econ (this issue). doi:10.1007/s00712-013-0348-2

Dixit AK, Pindyck RS (1994) Investment under uncertainty. Princeton University Press, Princeton

Dixit AK, Pindyck RS (1998) Expandability, reversibility, and optimal capacity choice. NBER Working Papers 6373, National Bureau of Economic Research, Inc

Mantovi A (2013) On the commutativity of expansion and substitution effects. J Econ (this issue). doi:10. 1007/s00712-013-0337-5

Tsekrekos A (2013) Irreversible exit decisions under mean-reverting uncertainty. J Econ (this issue). doi:10. 1007/s00712-013-0343-7 